\title{
Validated LC Method for the Estimation of Dorzolamide HCl (Carbonic Anhydrase Inhibitor) in Ophthalmic Solutions
}

\author{
A. NARENDRA*, D. DEEPIKA ${ }^{\#}$ AND M. MATHRUSRI ANNAPURNA ${ }^{\S}$
}

\author{
* Department of Pharmaceutical Analysis and Quality Assurance, \\ Roland Institute of Pharmaceutical Sciences, Berhampur, Orissa, India. \\ "Royal College of Pharmacy and Health Sciences, Berhampur, Orissa, India. \\ ${ }^{\S}$ GITAM Institute of Pharmacy, GITAM University, Visakhapatnam (A.P.), India. \\ naren_angirekula@yahoo.com
}

Received 25 July 2011; Accepted 20 September 2011

\begin{abstract}
A reverse phase HPLC method is described for the determination of Dorzolamide in eye drops. Chromatography was carried on an Inertsil ODS 3V column using Acetonitrile : (0.02M) 1, Octane Sulphonic acid buffer ( $\mathrm{pH} 3.5$ ) $(36: 64 \mathrm{v} / \mathrm{v})$ on isocratic mode at a flow rate of $1 \mathrm{~mL} / \mathrm{min}$ with UV detection at $254 \mathrm{~nm}$. The detector response was linear in the concentration range 4-720 $\mu \mathrm{g} / \mathrm{mL}$. The limit of detection and limit of quantification are found to be 0.7041 and $2.3483 \mu \mathrm{g} / \mathrm{mL}$ respectively. The method was validated as per the ICH guidelines. The proposed method is rapid, accurate and precise and can be applied for the routine analysis of dorzolamide in ophthalimic solutions.
\end{abstract}

Keywords: Dorzolamide (DRZ), RP-HPLC, Eye drops, ICH.

\section{Introduction}

Dorzolamide $^{1-3}$ (Figure 1) is a carbonic anhydrase (CA) inhibitor. Dorzolamide is a sulfonamide and a highly specific carbonic anhydrase II (CA-II) inhibitor, which is the main $\mathrm{CA}$ iso-enzyme involved in aqueous humor secretion. Inhibition of CA-II in the ciliary processes of the eye decreases aqueous humor secretion, presumably by slowing the formation of bicarbonate ions with subsequent reduction in sodium and fluid transport. It is indicated for the reduction of elevated IOP in patients with open-angle glaucoma or ocular hypertension who are insufficiently responsive to beta-blockers. It reduces IOP by approximately $17-23 \%$ in patients with elevater IOP. Dorzolamide ${ }^{4}$ (DRZ), chemically [( $4 S$, $6 \mathrm{~S}$ ) -4- (Ethylamino) -6-methyl- 5, 6- dihydro- $4 H$ thieno[2,3b] thiopyran- 2-sulphonamide 7, 7-dioxide hydrochloride] has a molecular formula $\mathrm{C}_{10} \mathrm{H}_{16} \mathrm{~N}_{2} \mathrm{O}_{4} \mathrm{~S}_{3}$ and molecular weight 324.44. Martens-Lobenhoffer ${ }^{5}$ et al studied the pharmacokinetics of DRZ where as Almeida ${ }^{6}$ et al reported the effects of DRZ on rabbit central corneal thickness. 
Literature survey reveals that liquid chromatographic ${ }^{7-8}$ methods, voltametric ${ }^{9}$, spectrophotometric $^{10}$ and simultaneous determination of DRZ along with timolol was reported by TLC-densitometry ${ }^{11}$, Ratio Derivative Spectrophotometery ${ }^{12}$ and capillary electrophoresis ${ }^{13}$ in ophthalmic preparations. The aim of the present work is to develop a LC method for the determination of Dorzolamide in ophthalmic solutions and to validate as per the ICH guidelines.

\section{Experimental}

Dorzolamide was obtained from Cipla Ltd. (India) as gift sample. DORTAS (2\%, $3 \mathrm{ml})$, DORZOX $(2 \%, 5 \mathrm{ml})$ and OCUDOR eye drops $(2 \%, 5 \mathrm{ml})$ brands are available in the local market. HPLC grade Acetonitrile (Merck) and 1- Octane Sulphonic acid (Spectrochem) and Ortho phosphoric acid were used for the entire work.

\section{Instrument}

Quantitative HPLC was performed on a binary gradient HPLC with Waters Alliance (Waters Corporation, MA, USA) equipped with a Waters 2695 separations module and a Waters 2695 PDA detector. Data acquisition was performed by the Empower pro-software operated on a Pentium ${ }^{\circledR}$ IV microprocessor. An Inertsil ODS 3V column $(250$ x $4.0 \mathrm{~mm}, 5 \mu$ mwas used.

\section{Chromatographic conditions}

The mobile phase composed of Acetonitrile : (0.02M) 1-Octane Sulphonic acid buffer (pH adjusted to 3.5 with o-phosphoric acid) was used in the ratio of $36: 64 \mathrm{v} / \mathrm{v}$ with flow rate of $1.0 \mathrm{ml} / \mathrm{min}$. The mobile phase was degassed and filtered through $0.2 \mu \mathrm{m}$ membrane filter before pumping into HPLC system. Analysis was carried out at $254 \mathrm{~nm}$. Preparation of standard stock and sample solutions

Accurately weighed $100 \mathrm{mg}$ of Dorzolamide pure drug was taken and dissolved in acetonitrile in a $100 \mathrm{~mL}$ volumetric flask and sonicated. The stock solution was further diluted with the mobile phase to get a series of solutions containing $4.0-720.0 \mu \mathrm{g} / \mathrm{mL}$ of DRZ.

\section{Validation}

\section{Linearity}

$10 \mu \mathrm{l}$ of each of the above prepared solutions $(4.0-720.0 \mu \mathrm{g} / \mathrm{mL})$ were injected in to the HPLC system and the peak area (Table 1) was recorded from the respective chromatograms. A representative chromatogram is shown in Figure 2.

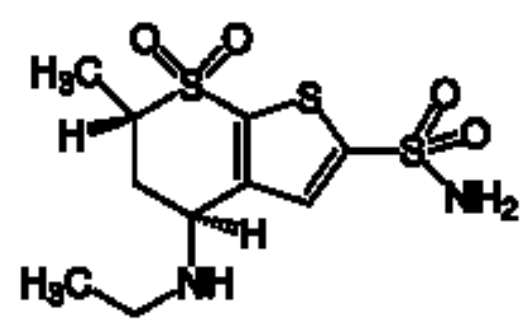

Figure 1. Chemical Structure of Dorzolamide (DRZ). 
A calibration graph was drawn by plotting the concentration of Dorzolamide $(\mu \mathrm{g} / \mathrm{mL})$ on $\mathrm{x}$-axis and the corresponding peak area on the y-axis (Figure 3).

\section{Assay of commercial formulations}

DORTAS $(2 \%, 3 \mathrm{ml})$, DORZOX $(2 \%, 5 \mathrm{ml})$ and OCUDOR eye drops $(2 \%, 5 \mathrm{ml})$ brands were purchased from the local market and required sample solutions were made using the mobile phase and $10 \mu \mathrm{L}$ of these formulation solutions were injected into the HPLC system and the peak areas were recorded. The results are given in Table 2.

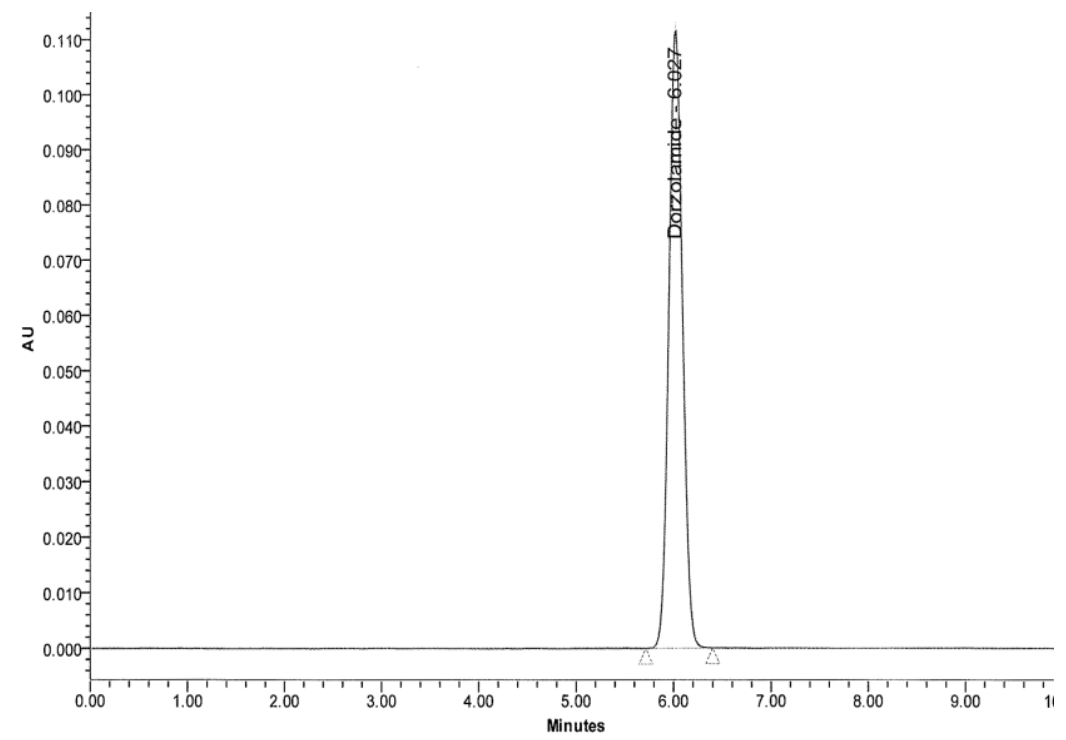

Figure 2. A typical chromatogram of Dorzolamide by RP- HPLC.

Table 1. Calibration data of Dorzolamide.

\begin{tabular}{ccc}
\hline $\begin{array}{c}\text { Concentration } \\
\mu \mathrm{g} / \mathrm{ml}\end{array}$ & $\begin{array}{c}\text { Average Peak } \\
\text { area }(\mathrm{n}=3)\end{array}$ & \% RSD \\
\hline 4 & 93857 & 0.141 \\
\hline 8 & 175677 & 0.876 \\
\hline 20 & 459296 & 0.324 \\
\hline 40 & 891999 & 0.193 \\
\hline 80 & 1792688 & 0.482 \\
\hline 160 & 3559260 & 0.391 \\
\hline 200 & 4412501 & 1.021 \\
\hline 240 & 5333088 & 0.813 \\
\hline 320 & 7093708 & 0.952 \\
\hline 400 & 8776995 & 0.923 \\
\hline 480 & 10432011 & 0.183 \\
\hline 560 & 12136319 & 0.632 \\
\hline 600 & 13184571 & 0.815 \\
\hline 720 & 15813771 & 0.867 \\
\hline
\end{tabular}




\section{Precision}

The precision of an analytical procedure expresses the degree of scatter between a series of measurements obtained from multiple sampling of the same homogeneous sample under the prescribed conditions. The repeatability (intra-day precision) refers to the use of analytical procedure within a laboratory over a short period of time using the same operator with the same equipment. Intermediate precision (inter-day precision) involves estimation of variations in analysis when a method is used within a laboratory on different days, by different analysts.

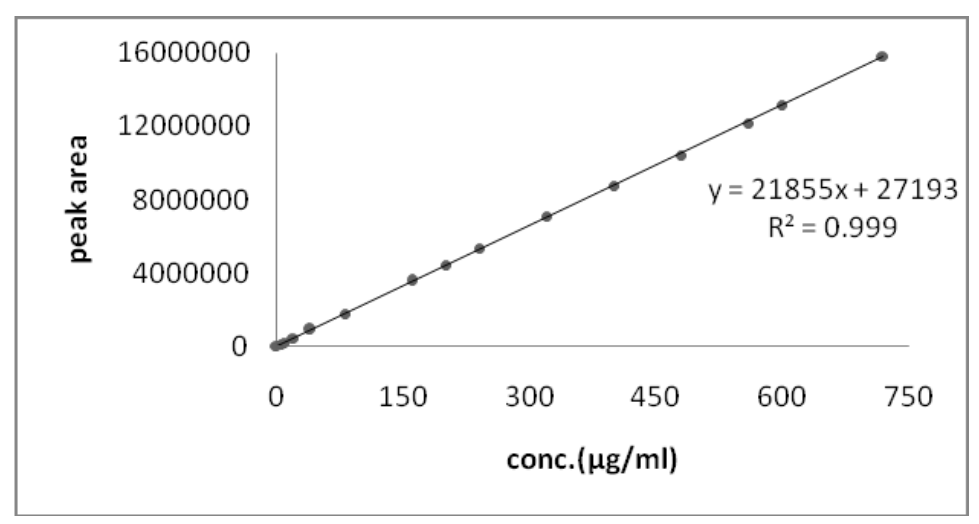

Figure 3. Calibration curve of Dorzolamide by RP- HPLC.

Table 2. Analysis of commercial formulations (Eye Drops).

\begin{tabular}{cccc}
\hline $\begin{array}{l}\text { Commercial } \\
\text { Formulation }\end{array}$ & Labeled amount & Amount found & \\
& $(\%)$ & $(\%)$ & \% Recovery \\
\hline Brand I & 2 & 1.9866 & $99.33 \pm 0.25$ \\
\hline Brand II & 2 & 1.9870 & $99.35 \pm 0.16$ \\
\hline Brand III & 2 & 1.9916 & $99.58 \pm 0.19$ \\
\hline
\end{tabular}

*Average of six determinations.

Table 3. Intra and inter - day precision for Dorzolamide $(n=3)$.

\begin{tabular}{ccccc}
\hline \multirow{2}{*}{ Conc. $(\mu \mathrm{g} / \mathrm{ml})$} & \multicolumn{2}{c}{ Intra-day precision } & \multicolumn{2}{c}{ Inter-day precision } \\
\cline { 2 - 5 } & Mean Peak Area & RSD (\%) & & RSD (\%) \\
\hline \multirow{2}{*}{200} & $\begin{array}{c}4401577 \pm \\
501779.78\end{array}$ & 0.114 & $4439270 \pm 40530.54$ & 0.913 \\
\hline \multirow{2}{*}{400} & $\begin{array}{c}8784338 \pm \\
59118.59\end{array}$ & 0.673 & $8837998 \pm 72648.34$ & 0.822 \\
\hline \multirow{2}{*}{600} & $\begin{array}{c}13169381 \pm \\
48068.24\end{array}$ & 0.365 & $\begin{array}{c}12988022 \pm \\
132607.70\end{array}$ & 1.021 \\
\hline
\end{tabular}


The intra-day repeatability was investigated using three separate sample solutions each at three different levels $\left(200,400\right.$ and $\left.600 \mu \mathrm{g} \mathrm{mL}^{-1}\right)$ prepared as reported above, from the freshly reconstructed formulations. Each solution was injected in triplicate and the peak areas obtained were used to calculate means and RSD\% values (Table 3).

The inter-day reproducibility was checked on three different days, by preparing and analyzing in triplicate four separate sample solutions from the reconstructed formulations at the same concentration level of intra-day repeatability; the means and $\mathrm{RSD} \%$ values were calculated from peak areas.

\section{Accuracy}

The accuracy of an analytical method is the closeness of the test results to the true value. To assess accuracy, freshly prepared placebo of the DRZ pharmaceutical formulations were spiked with various amounts of pure DRZ at 80, 100 and $120 \%$. Each solution was injected in triplicate and the peak areas were used to calculate means and RSD\% values (Table 4) and compared with those obtained with standard DRZ solutions.

Table 4. Accuracy - Recovery data for Dorzolamide $(n=3)$.

\begin{tabular}{ccccc}
$\begin{array}{c}\text { Amount }(\%) \\
\text { of drug added } \\
\text { to analyte }\end{array}$ & $\begin{array}{c}\text { Theoretical } \\
\text { content }\end{array}$ & $\begin{array}{c}\text { Mean Conc. } \\
\text { found } \\
\left(\mu \mathrm{g} \mathrm{mL}^{-1}\right)\end{array}$ & $\begin{array}{c}\text { \% Recovery } \\
\left(\mu \mathrm{gL}^{-1}\right) \pm S D\end{array}$ & \% RD \\
\hline 80 & 360 & $360.13 \pm 0.645$ & 100.04 & 0.1792 \\
\hline 100 & 400 & $395.43 \pm 1.367$ & 98.86 & 0.3459 \\
\hline 120 & 440 & $438.83 \pm 1.079$ & 99.73 & 0.2459 \\
\hline
\end{tabular}

\section{Results and Discussion}

The analysis of the chromatogram of Dorzolamide revealed the following efficiencies of the column: for Dorzolamide $\mathrm{N}=8676$ (where $\mathrm{N}$ represents theoretical plate number) and asymmetry 1.05. The limit of detection (LOD) and limit of quantification (LOQ) for Dorzolamide were found to be 0.7041 and $2.348 \mu \mathrm{g} / \mathrm{mL}$ respectively. The retention time of Dorzolamide was found to be $6.027 \mathrm{~min}$. The linearity was followed in the concentration range of of $4.0-720.0 \mu \mathrm{g} / \mathrm{mL}$ with regression equation $\mathrm{y}=21855 \mathrm{x}+27183$ and correlation coefficient 0.999 . The method is precise [0.822-1.021] (Inter-day) and 0.144-0.673 (Intraday)] and accurate (0.1792-0.3459) as the RSD values were less than $2 \%$. The percentage of purity of Dorzolamide in commercial formulations is found to be 99.33-99.58. 


\section{Conclusion}

The proposed liquid chromatographic method is simple, rapid, reproducible and economical for the analysis of Dorzolamide in pharmaceutical formulations and can be used successfully applied for the quantitative analysis of Dorzolamide in pharmaceutical formulations.

\section{Acknowledgement}

Authors are grateful to Chandra labs, Hyderabad for providing research facilities. The authors are also thankful to Cipla Ltd. (India) for providing gift samples of the pure drug.

\section{References}

1. Grover S, Apushkin MA, Fishman GA, Am. J. Ophthalmol., 2006, 141(5), 850.

2. Balfour J A, Wilde M I, Drugs Aging, 1997, 10(5), 384.

3. Ponticello G S, Sugrue M F, Plazonnet B, Durand-Cavagna G, Pharm Biotechnol., 1998, 11, 555.

4. The Merck Index, An Encyclopedia of Chemicals, Drugs and Biologicals, Maryadele J.O' Neil. Eds, $14^{\text {th }}$ Ed., Published by Merck Research Laboratories, Division of Merck and Co. Inc., Whitehouse Station, NJ, 2006, Monograph No. $3426,579$.

5. Martens-Lobenhoffer J, Banditt P, Clin Pharmacokinet. 2002, 41(3), 197.

6. Almeida G C Jr, Faria e Souza S J, Braz J Med Biol Res., 2006, 39(2), 277.

7. Sharath H. M. , Channabasavaraj K. P, Jose G. Babu, Jagadish S. Modiya, International Journal of Pharmacy And Pharmaceutical Sciences, 2011, 3(3), 100.

8. $\quad$ Erk N, Pharmazie, 2003, 58(7), 491.

9. N Erk, Die Pharmazie, 2003, 58(12), 870.

10. H. M. Sharath*, G babu Jose, K. P. Channabasavaraj, J. S. Modiya, International Journal of Pharmaceutical Sciences and Research, 2011, 2(4), 948.

11. Nevin Erk. J Pharm Biomed Anal, 2002, 28(2), 391.

12. Lories IB. J Pharm Biomed Anal, 2002, 27(5), 737.

13. Ismail, Palabiyik; Mehmet, Caglayan; Feyyaz, Onur, Chromatographia, 2011, 73 (5), 541 .

14. International Conference on Harmonization of Technical Requirements for Registration of Pharmaceuticals for Human Use (Nov. 6,) Validation of Analytical Procedures: Methodology, ICH Steering Committee, Geneva, Switzerland. 1996. 


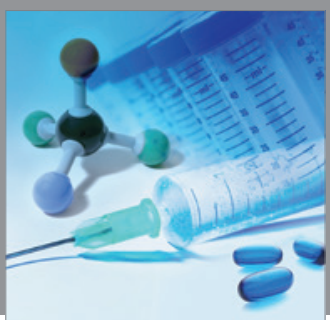

International Journal of

Medicinal Chemistry

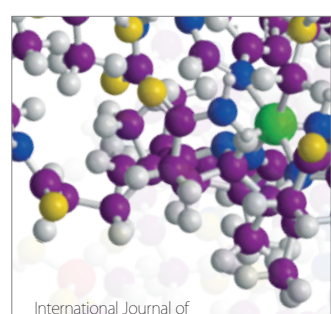

Carbohydrate Chemistry

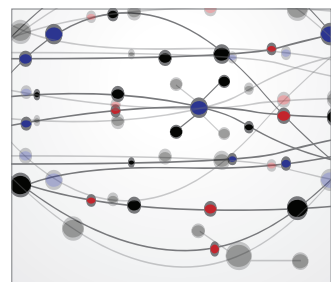

The Scientific World Journal
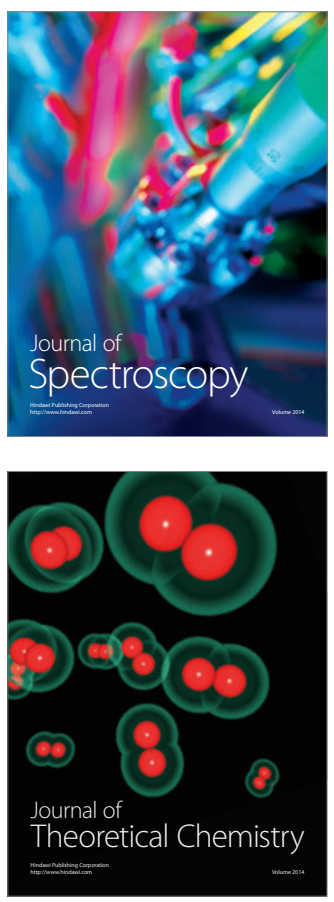
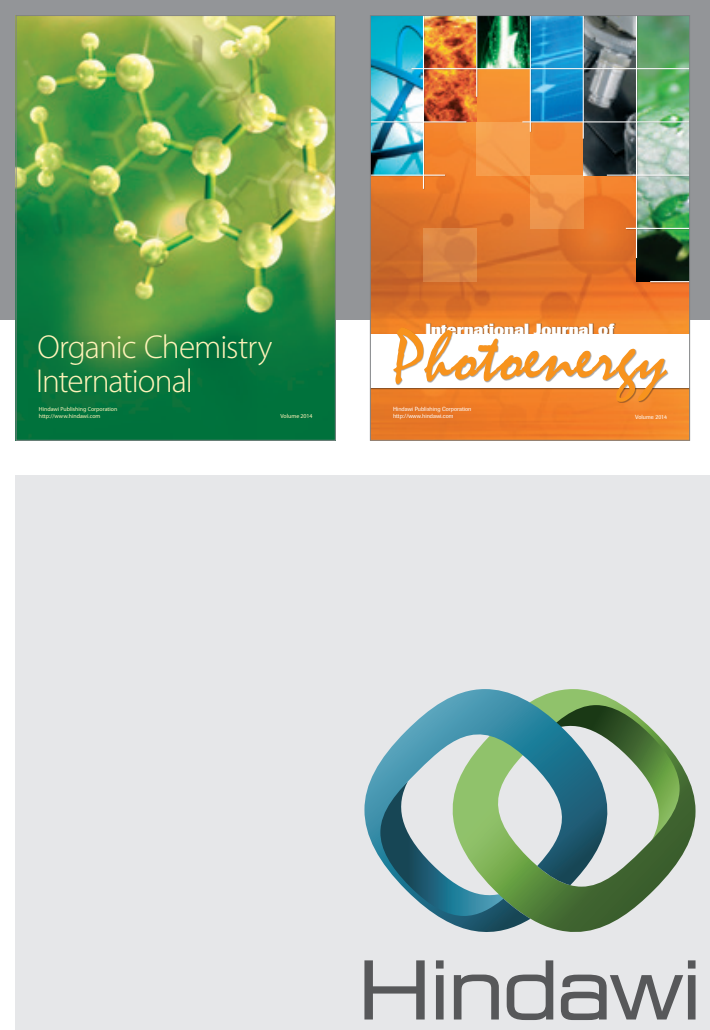

Submit your manuscripts at

http://www.hindawi.com
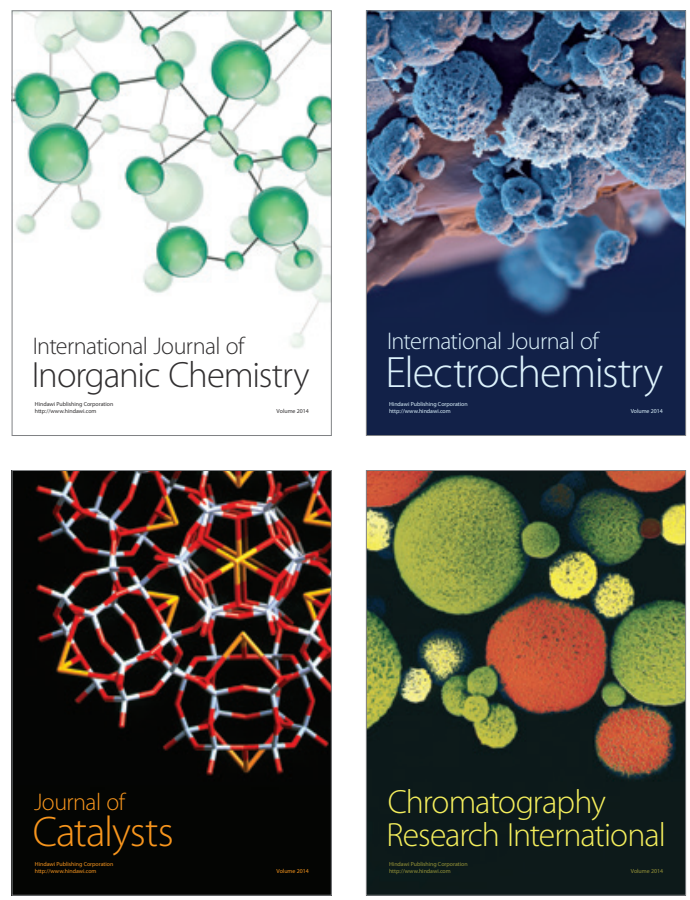
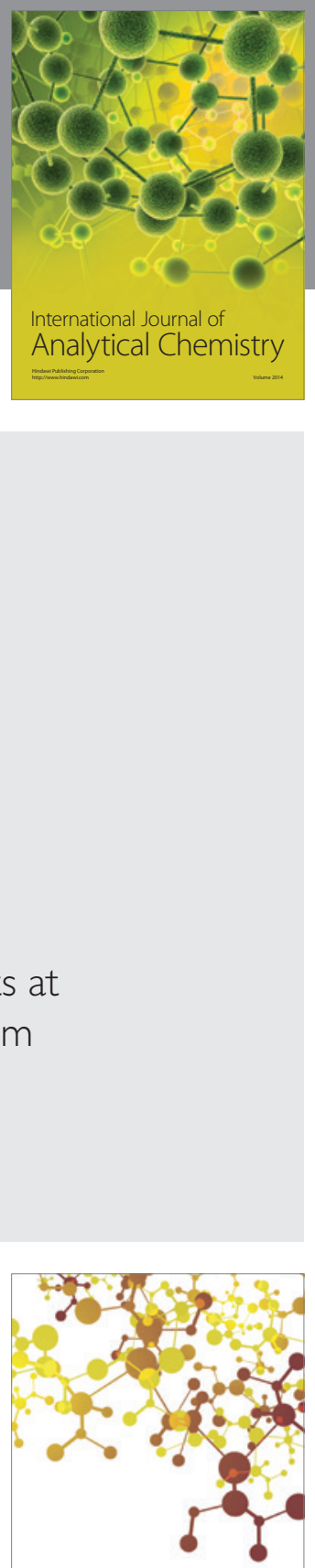

Journal of

Applied Chemistry
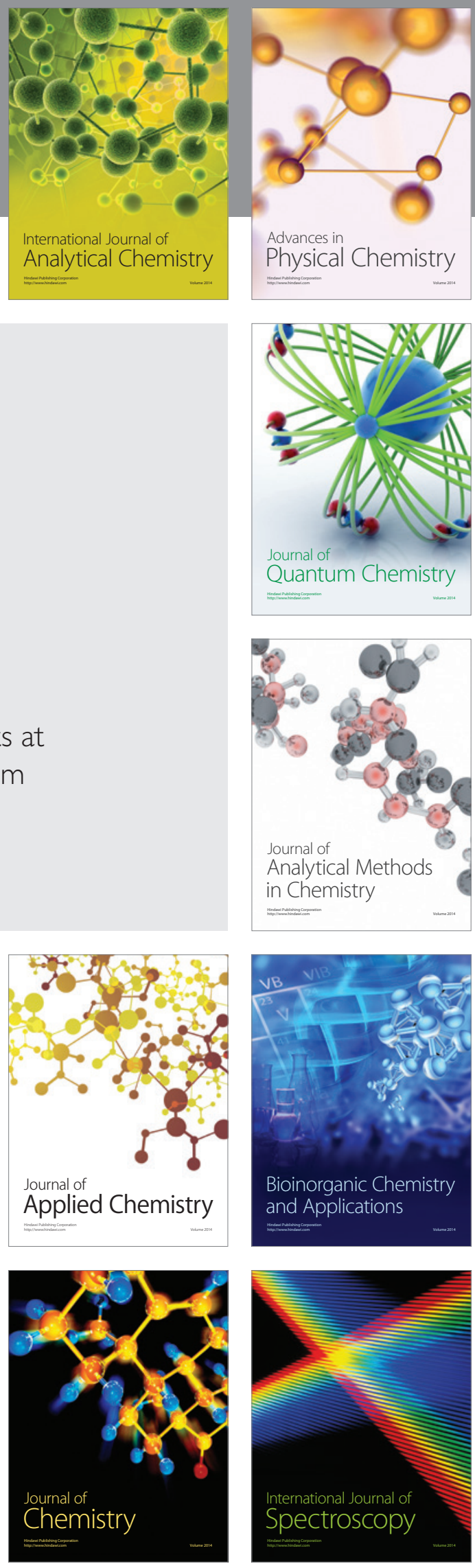